\title{
18F-FDG PET/CT in the diagnosis of Takayasu's arteritis
}

\author{
Gokhan Sargin, Taskin Senturk, Ongun Sahin
}

Department of Rheumatology, Medical Faculty, Adnan Menderes University, Aydin, Turkey

Submitted: 18 August 2016

Accepted: 10 September 2016

Arch Med Sci 2018; 14, 5: 1173-1174

DOI: https://doi.org/10.5114/aoms.2018.76140

Copyright @ 2018 Termedia \& Banach

Takayasu's arteritis (TA) is a chronic inflammatory vasculitis that predominantly affects the aorta, pulmonary artery and its main branches. The diagnostic criteria used by the American College of Rheumatology (ACR) include clinical signs that inflammatory and stenotic events. It may be difficult to diagnose TA according to the 1990 ACR Classification criteria despite high specificity and sensitivity [1]. Recently, studies have focused on the role of ${ }^{18} \mathrm{~F}$-fluorodeoxyglucose (FDG)-positron emission tomography $(\mathrm{PET}) /$ computed tomography $(\mathrm{CT})$ in the diagnosis of TA. ${ }^{18} \mathrm{~F}-\mathrm{FDG}$ PET/CT may be useful to determine the degree of inflammation and affected areas. Here we present a 57-year-old male patient who was diagnosed with TA with FDG-PET in the early active inflammatory phase.

A 57-year-old male patient presented to our clinic with high fever lasting more than 6 months. His body temperature was $38.9^{\circ} \mathrm{C}$, blood pressure was 165/80 mm Hg (right arm) and 140/65 mm Hg (left arm), and brachial artery pulse was $82 /$ min on physical examination. He had no medical history of taking any drugs except ramipril. The laboratory results were as follows: hemoglobin: $10.5 \mathrm{~g} / \mathrm{dl}, \mathrm{MCV}: 71.8 \mathrm{fl}$, leukocytes: $15890 / \mathrm{mm}^{3}$ (75\% neutrophils), platelets: 562 000/ $\mathrm{mm}^{3}$, erythrocyte sedimentation rate: $91 \mathrm{~mm} / \mathrm{h}$, C-reactive protein: $93.75 \mathrm{mg} / \mathrm{dl}$, alanine aminotransferase: $40 \mathrm{U} / \mathrm{l}$, total bilirubin: $0.3 \mathrm{mg} / \mathrm{dl}$, albumin: $3.5 \mathrm{~g} / \mathrm{dl}$, globulin: $2.8 \mathrm{~g} / \mathrm{dl}$, creatinine: $0.98 \mathrm{mg} / \mathrm{dl}$ and procalcitonin: $0.28 \mathrm{ng} / \mathrm{ml}$. Serum electrophoresis was compatible with polyclonal gammopathy. Urine examination, complements, Salmonella tube agglutination, Brucella tube agglutination, blood-urine cultures, autoimmune and viral serological markers were negative. The chest $X$-ray revealed no pathologic findings and increased echogenicity was detected around the infrarenal aorta by abdominal ultrasound. There was no evidence for decreased blood flow of the bilateral common, external and internal carotid artery, abdominal aorta or bilateral iliac arteries on magnetic resonance (MR) angiography. ${ }^{18} \mathrm{~F}-\mathrm{FDG}$ PET/CT was planned in patient who had unexplained systemic inflammation, high fever, and hypertension. Images showed diffuse and increased FDG uptake (SUVmax: 9.1) in the bilateral common carotid artery, subclavian artery, arcus aorta, thoracic aorta, abdominal aorta, the common iliac arteries and femoral artery. $1 \mathrm{mg} / \mathrm{kg} /$ day prednisolone was started with the diagnosis of TA. Clinical symptoms improved after treatment and high levels of inflammatory markers declined to normal ranges.

Magnetic resonance and FDG-PET are promising imaging methods in addition to classic angiography in TA (Figure 1). FDG-PET is more reliable compared with MR in the evaluation of disease activation during immunosuppressive therapy [2]. The presence of hypertension, weakness

\author{
Corresponding author: \\ Gokhan Sargin \\ Department \\ of Rheumatology \\ Adnan Menderes \\ University Medical \\ Faculty \\ 09000 Aydin, Turkey \\ Phone: +90 5534241097 \\ E-mail: gokhan_sargin@ \\ hotmail.com
}




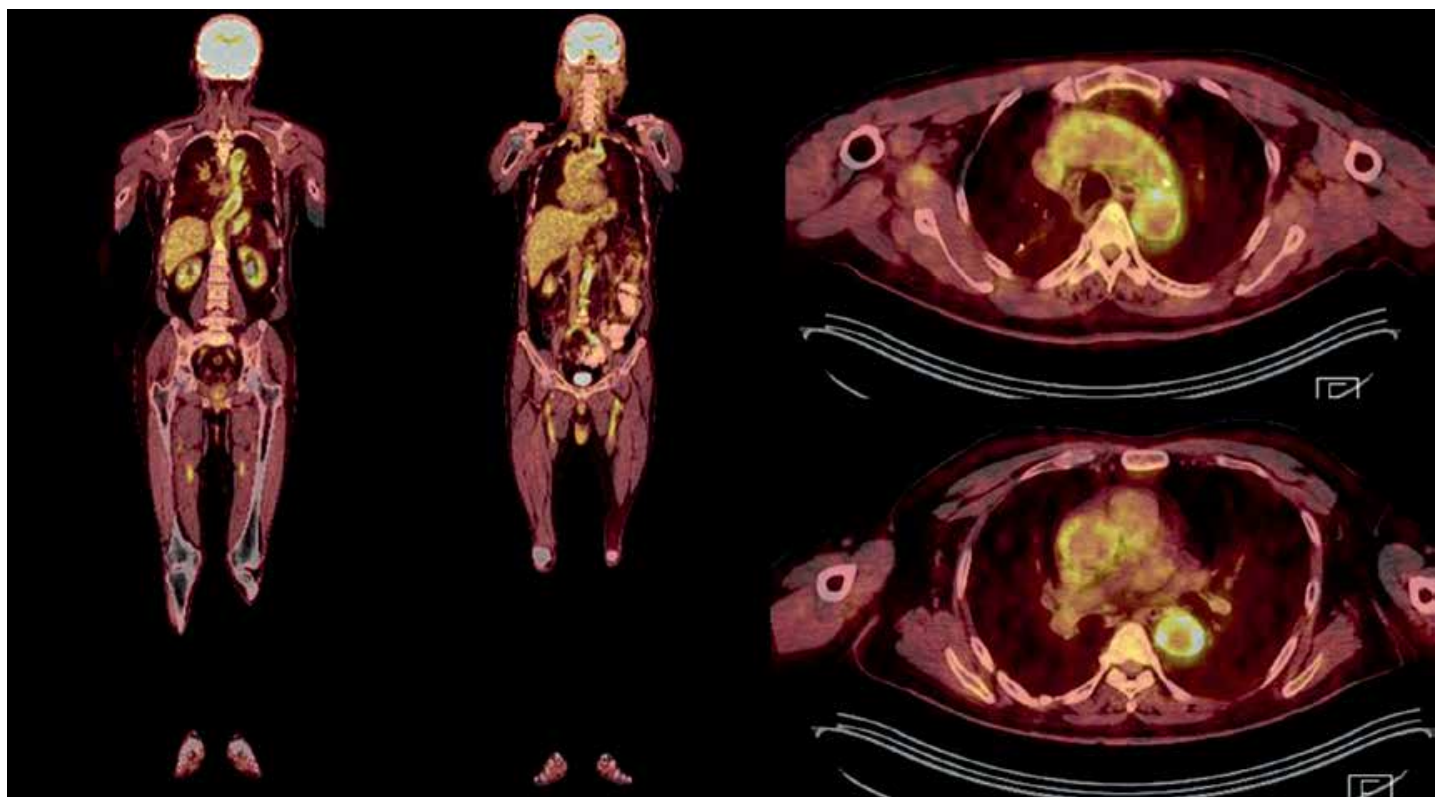

Figure 1. Diffuse increased FDG uptake in bilateral common carotid artery, subclavian artery, aortic arch, thoracic and abdominal aorta, bilateral common iliac arteries and femoral arterial walls in FDG-PET

of the peripheral pulses, pressure difference between the two arms and arterial murmur are stimulating in terms of vasculitis in patients who have systemic inflammation and fever. FDG-PET can be helpful for clinicians in early diagnosis of TA but not in routine use.

\section{Conflict of interest}

The authors declare no conflict of interest.

\section{References}

1. Jennette JC, Falk RJ, Bacon PA, et al. 2012 revised International Chapel Hill Consensus Conference Nomenclature of Vasculitides. Arthritis Rheum 2013; 65: 1-11.

2. Meller J, Strutz F, Siefker U, et al. Early diagnosis and follow-up of aortitis with [18F] FDG PET and MRI. Eur J Nucl Med Mol Imaging 2003; 30: 730-6. 